\title{
Influence of miR-221/222 on cardiomyocyte calcium handling and function
}

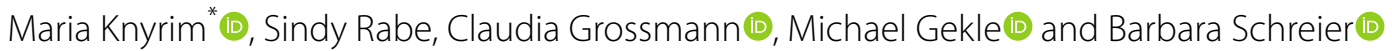

\begin{abstract}
Background: Cardiovascular disease is the leading cause of death worldwide. Cardiac electrical remodeling including altered ion channel expression and imbalance of calcium homeostasis can have detrimental effects on cardiac function. While it has been extensively reported that miR-221/222 are involved in structural remodeling, their role in electrical remodeling still has to be evaluated. We previously reported that subunits of the L-type $\mathrm{Ca}^{2+}$ channel (LTCC) are direct targets of miR-221/222. Furthermore, $\mathrm{HL}-1$ cells transfected with miR-221 or -222 mimics showed a reduction in LTCC current density while the voltage-dependence of activation was not altered. The aim of the present study was to determine the influence of miR-221/222 on cardiomyocyte calcium handling and function.

Results: Transient transfection of HL-1 cells with miR-221/222 mimics led to slower depolarization-dependent $\mathrm{Ca}^{2+}$ entry and increased proportion of non-responding cells. Angiotensin II-induced $\mathrm{Ca}^{2+}$ release from the SR was not affected by miR-221/222. In miR-222-transfected neonatal cardiomyocytes the isoprenaline-induced positive inotropic effect on the intracellular $\mathrm{Ca}^{2+}$ transient was lost and the positive chronotropic effect on spontaneous beating activity was strongly reduced. This could have severe consequences for cardiomyocytes and could lead to a reduced contractility and systolic dysfunction of the whole heart.

Conclusions: This study adds a new role of miR-221/222 in cardiomyocytes by showing the impact on $\beta$-adrenergic regulation of LTCC function, calcium handling and beating frequency. Together with the previous report that miR221/222 reduce GIRK1/4 function and LTCC current density, it expands our knowledge about the role of these miRs on cardiac ion channel regulation.
\end{abstract}

Keywords: miR-221/222, Cardiomyocytes, Remodeling, L-type Ca ${ }^{2+}$ channel

\section{Background}

Cardiac remodeling comprises all changes in molecular, cellular and interstitial composition of the heart and can lead to cardiac dysfunction, malignant arrhythmias, sudden cardiac arrest or heart failure [1]. More specific, electrical remodeling includes altered ion channel expression and imbalance of calcium homeostasis [2]. All together these molecular changes can lead to cardiac dysfunction, malignant arrhythmias, sudden cardiac arrest or heart failure [1]. Aberrant microRNA (miR) expression has

*Correspondence: maria.knyrim@medizin.uni-halle.de Julius-Bernstein-Institute of Physiology, Martin Luther University HalleWittenberg, Magdeburger Str. 6, 06110 Halle (Saale), Germany been implicated in cardiac remodeling and disease [3]. miR-221/222 are among the miRNAs involved in these processes.

In the last decade our understanding of miR-221/222 in remodeling has deepened but whether these miRs are detrimental or beneficial is still unclear. MiR-221/222 are clustered miRNAs that share the same seed sequence [4]. They are ubiquitously expressed and conserved between e.g. mouse and human [3]. Although miR-221/222 do not belong to cardiac-enriched miRs like miR-1, miR-133, miR-208 and miR-499, they are also involved in cardiac pathology [3]. The role of miR-221/222 in cardiac remodeling is discussed highly controversial. Several studies show that miR-221/222 are linked to cardiac hypertrophy original author(s) and the source, provide a link to the Creative Commons licence, and indicate if changes were made. The images or other third party material in this article are included in the article's Creative Commons licence, unless indicated otherwise in a credit line to the material. If material is not included in the article's Creative Commons licence and your intended use is not permitted by statutory regulation or exceeds the permitted use, you will need to obtain permission directly from the copyright holder. To view a copy of this licence, visit http://creativecommons.org/licenses/by/4.0/. The Creative Commons Public Domain Dedication waiver (http://creativeco mmons.org/publicdomain/zero/1.0/) applies to the data made available in this article, unless otherwise stated in a credit line to the data. 
$[5,6]$. Furthermore, studies investigating tissue or circulating miR-221/222 expression as potential biomarkers for cardiovascular disease suggested that miR-221/222 levels are associated with disease state [7-10], or cardiovascular risk [11]. In line with this, cardiac-specific overexpression of either miR-221 or miR-222 led to cardiac hypertrophy, cardiac fibrosis, apoptosis, reduced autophagy and development of heart failure (HF) in mice $[12,13]$. However, other studies attribute a more cardioprotective role to miR-221/222 [6, 14-21]. Our group previously demonstrated that miR-221/222 are upregulated in the hearts of mice with either genetically (EGFR $\mathrm{KO}$ ) or pharmacologically (angiotensin II) induced heart hypertrophy [22].

Among other findings, we demonstrated (i) that mRNA expression of the L-type $\mathrm{Ca}^{2+}$ channel (LTCC) subunits Cacna1c, Cacnb2 and Cacna2d1 was decreased in these hearts, (ii) that the 3'-UTRs of Cacna1c and Cacnb2 are direct targets of these miRNAs and (iii) that miR-221/222 mimics reduce LTCC current density in whole cell patch clamp recordings of HL-1 cells [22]. Thus, miR-221/222 contribute to cardiac electrical remodeling by reducing LTCC-mediated $\mathrm{I}_{\mathrm{Ca}, \mathrm{L}}$ current.

In the heart, the LTCC mediates action potential (AP) conduction as well as excitation-contraction coupling in cardiomyocytes and is therefore crucial for cardiac function. Accordingly, cardiac disease is often associated with LTCC remodeling [23-25]. The physiological adaptation of the $\mathrm{I}_{\mathrm{Ca}, \mathrm{L}}$ to biological needs is mediated by a high variety of signaling pathways and mechanisms that converge at modulating LTCC function. The most important modulators include $\beta$-adrenergic signaling, intracellular $\mathrm{Ca}^{2+}$ concentration and membrane voltage [26]. LTCC remodeling includes differential expression, function and regulation of this channel. Unresponsiveness to $\beta$-adrenergic stimulation is one hallmark of the failing heart [27] and may be caused in part by altered LTCC expression.

Since miR-221/222 directly regulate the LTCC and thereby the $\mathrm{I}_{\mathrm{Ca}, \mathrm{L}}[22]$, the aim of the present study was to determine the influence of miR-221/222 on cardiomyocyte calcium handling and function, including response to $\beta$-adrenergic stimulation and spontaneous beating frequency. Thereby miR-221/222 could affect physiological and pathophysiological adaptation of the cardiac output.
In this study we demonstrate that transfection of HL-1 cells with miR-221/222 led to slower depolarization-dependent $\mathrm{Ca}^{2+}$ entry and increased proportion of non-responding cells. AngII-induced $\mathrm{Ca}^{2+}$ release from the SR was not affected by miR-221/222. In miR222-transfected neonatal cardiomyocytes (neoCM) the isoprenaline (ISO)-induced positive inotropic effect on the intracellular $\mathrm{Ca}^{2+}$ transient was lost and the positive chronotropic effect on spontaneous beating activity was strongly reduced. Thus, we here demonstrate a novel role of miR-221/222 in cardiomyocytes.

\section{Results \\ LTCC-mediated $\mathrm{Ca}^{2+}$ influx is slower in miR-transfected HL-1 cells}

We previously reported that subunits of the L-type $\mathrm{Ca}^{2+}$ channel are direct targets of miR-221/222. To investigate if this regulation has an impact on cardiomyocyte calcium handling, $\mathrm{Ca}^{2+}$ homeostasis was analysed by ratiometric fluorescence microscopy in HL-1 cells. Two different mechanisms to increase cytosolic $\mathrm{Ca}^{2+}$ concentrations were tested: (1) a depolarization-independent increase mediated by AngII, followed by (2) a depolarization-dependent increase due to elevated extracellular $\mathrm{K}^{+}$concentration. The sequence of stimulation and typical cellular reactions are depicted in Fig. 1A. AngII was used to investigate depolarization-independent effects of miR-221/222 on intracellular calcium release. Application of AngII evokes a transient increase in intracellular calcium concentration via an IP3/SR-dependent mechanism [28]. Superfusion with $25 \mathrm{mM} \mathrm{KCl}$ leads to cell membrane depolarization and subsequent LTCC activation causing a constantly increasing intracellular $\mathrm{Ca}^{2+}$ concentration up to a plateau level (baseline shift). To discriminate between dead cells and cells not responding to the respective stimuli, the calcium ionophore ionomycin was added to the superfusion at the end of each experiment. Living cells that do not respond to AngII and/or $\mathrm{KCl}$ still react to ionomycin with an increase in cytosolic $\mathrm{Ca}^{2+}$ concentrations. Dead cells on the other hand no longer have an intact plasma membrane, leading to an early accumulation of calcium in the cytosol and therefore no pronounced response upon ionomycin application.

\footnotetext{
(See figure on next page.)

Fig. 1 LTCC-mediated increase in cytosolic $\left[\mathrm{Ca}^{2+}\right]$ is slower in miR-221/222-transfected HL-1 cells. A Scheme of the applied superfusion protocol and typical response of a cell to $100 \mathrm{nM}$ Angll, $25 \mathrm{mM} \mathrm{KCl}$ and $1 \mu \mathrm{M}$ ionomycin (mimic control). Grey areas indicate areas used for calculation of area under the curve (AUC). B-D Angll elicits a transient increase in $\left[\mathrm{Ca}^{2+}\right]_{\mathrm{i}}$. Peak height, percentage of non-responding cells and AUC are not significantly altered compared to mimic control. $\mathbf{E}-\mathbf{H ~ K C l}$ leads to a baseline shift of $\left[\mathrm{Ca}^{2+}\right]_{i}$ up to a plateau level. The baseline shift is reduced by trend by miR-221/222. The area under the curve is significantly reduced in miR-221-transfected cells and miR-221/222 both lead to a significantly slower increase in $\left[\mathrm{Ca}^{2+}\right]_{i}$ up to the plateau level. The time to max. is also shown in representative tracings ( $\mathbf{F}$, right side). The proportion of non-responding cells is significantly increased in miR-221-transfected cells. Straight line indicates median, dotted line indicates mean, ${ }^{*} p<0.05$, $N=13-14$ experiments per group (single data points), $n=27-115$ cells per experiment. $m c$ mimic control
} 
A

\begin{tabular}{|l|c|c|c|c|c|}
\hline Ringer & AngII & Ringer & $\mathrm{KCl}$ & Ringer & Ionomycin \\
\hline $\begin{array}{c}\text { A.30 } \\
1.25\end{array}$ & transient
\end{tabular}

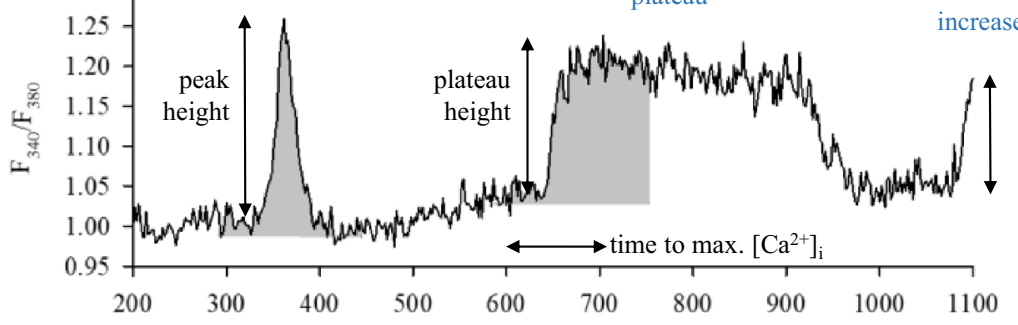

ime [s]

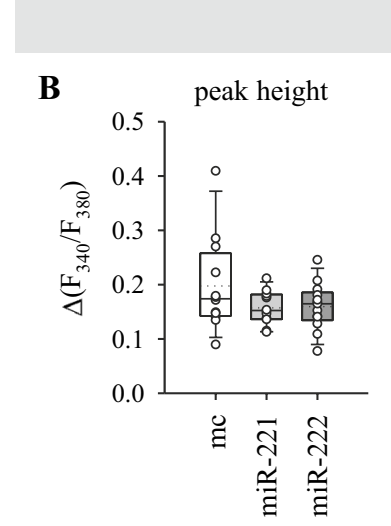

C AUC
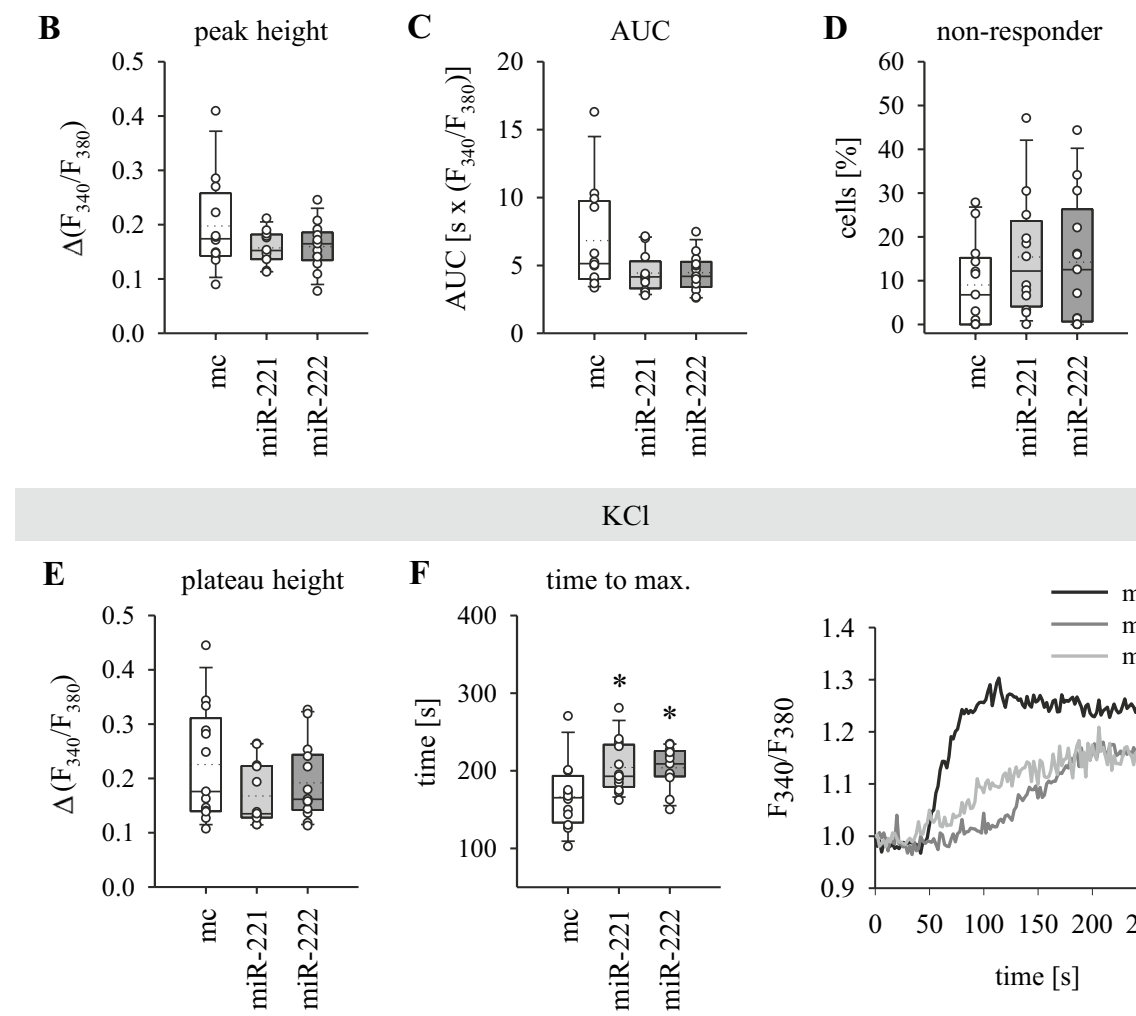

$\mathrm{KCl}$
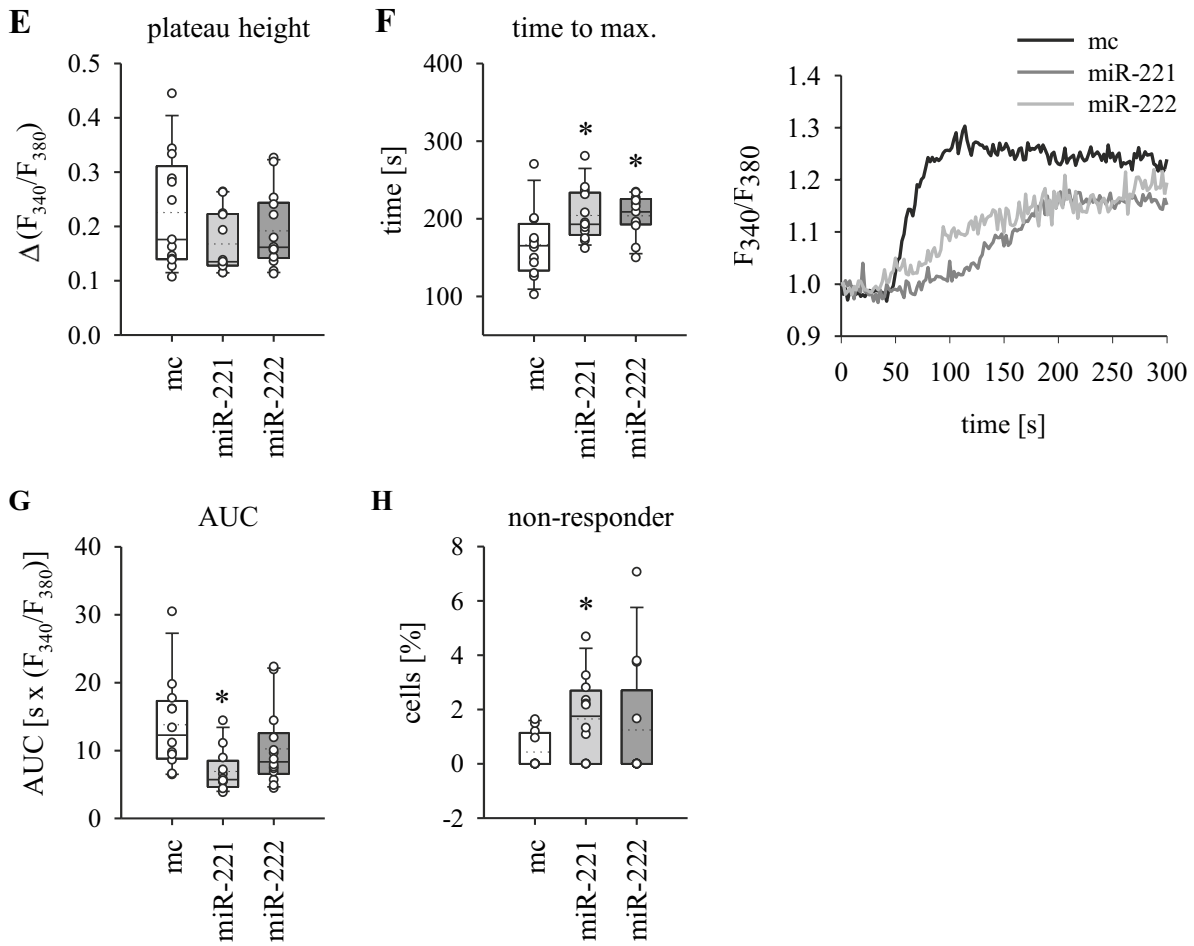

Fig. 1 (See legend on previous page.) 
Transfection of HL-1 cells with miR-221 or -222 has no impact on the AngII-induced calcium transient (Fig. 1B, $\mathrm{C})$, neither on peak height [mimic control (mc): $0.20 \pm$ 0.03; miR-221: $0.16 \pm 0.01 ; \mathrm{miR}-222: 0.16 \pm 0.01 \Delta\left(\mathrm{F}_{340} /\right.$ $\left.\mathrm{F}_{380}\right)$, nor on the area under the curve [mc: $6.84 \pm 1.12$; miR-221: $4.45 \pm 0.41$; miR-222: $4.48 \pm 0.38\left(\mathrm{~F}_{340} / \mathrm{F}_{380}\right)$ $\mathrm{s}]$. Furthermore, the percentage of cells not responding to AngII is not affected by miR-221/222 (Fig. 1D; mc: $9.06 \pm 2.71 \%$; miR-221: $15.43 \pm 3.96 \%$; miR-222: $14.25 \pm 4.10 \%$ ). Thus, miR-221/222 do not interfere with AngII-mediated depolarization-independent calcium signalling in HL-1 cells.

In contrast to this, LTCC-dependent calcium signalling is altered by miR-221/222. The $\mathrm{KCl}$-induced baseline shift [Fig. 1E; mc: $0.23 \pm 0.03$; miR-221: $0.17 \pm$ 0.02; miR-222: $\left.0.19 \pm 0.02 \Delta\left(\mathrm{F}_{340} / \mathrm{F}_{380}\right)\right]$ is decreased by trend by miR-221 and -222 . The area under the curve [Fig. 1G; mc: $13.82 \pm$ 1.98; miR-221: $6.94 \pm 0.90$; miR222: $\left.10.28 \pm 1.52\left(\mathrm{~F}_{340} / \mathrm{F}_{380}\right) \mathrm{s}\right]$ is significantly reduced in miR-221-transfected cells and the time needed to reach maximum plateau $\mathrm{Ca}^{2+}$ levels is significantly prolonged by both miRs compared to control (Fig. 1F; mc: $166.80 \pm$ $12.65 \mathrm{~s} ;$ miR-221: $204.59 \pm 9.37 \mathrm{~s}$; miR-222: $204.22 \pm$ 7.27 s). Additionally, miR-221 significantly increased the proportion of non-responding cells (Fig. $1 \mathrm{H}$; mc: $0.44 \pm$ 0.19\%; miR-221: $1.66 \pm 0.44 \%$; miR-222: $1.25 \pm 0.62 \%$ ). These results show that miR-221/222 reduce depolarization-dependent $\mathrm{Ca}^{2+}$ influx in HL-1 cells.

To verify that AngII- and $\mathrm{KCl}$-induced calcium signals are indeed mediated by AT1R and LTCC, respectively, experiments with appropriate inhibitors were performed in untransfected HL-1 cells (Fig. 2). AT1R inhibitor losartan significantly reduces the AngII-induced calcium transient in comparison to control-treated cells (Fig. 2). Due to an increased population of cells that are no longer responding to AngII upon losartan application (Fig. 2C; losartan: $55.45 \pm 13.78 \%$ vs control: $19.16 \pm 9.63 \%$ ), the overall peak height of all cells [Fig. 2A; losartan: $0.06 \pm$ 0.02 vs control: $\left.0.19 \pm 0.03 \Delta\left(\mathrm{F}_{340} / \mathrm{F}_{380}\right)\right]$ is even more reduced than that of the population of responding cells [Fig. 2B; losartan: $0.08 \pm 0.004$ vs control: $0.21 \pm 0.001$ $\left.\Delta\left(\mathrm{F}_{340} / \mathrm{F}_{380}\right)\right]$. LTCC blocker verapamil prevents the $\mathrm{KCl}-$ induced intracellular calcium increase by enlarging the population of non-responding cells (Fig. 2E; verapamil: $86.67 \pm 5.25 \%$ vs control: $3.53 \pm 1.97 \%$ ). In line with this, when considering the overall response of all cells, the plateau height is dramatically reduced in verapamiltreated cells [Fig. 2D; verapamil: $0.03 \pm 0.002$ vs control: $\left.0.18 \pm 0.007 \Delta\left(\mathrm{F}_{340} / \mathrm{F}_{380}\right)\right]$. Both losartan and verapamil diminish the response elicited under control conditions. Thus, the observed cellular calcium response to AngII and $\mathrm{KCl}$ is indeed mediated by AT1R and LTCC, respectively.
In conclusion, the results of calcium measurements in HL-1 cells indicate that miR-221/222 do not influence the IP3/SR-mediated cytosolic calcium increase but have an effect on the depolarization-dependent (e.g., action potential-dependent) intracellular calcium increase in cardiomyocytes. Thus, downregulation of LTCCs by miR$221 / 222$ may have an effect on depolarization kinetics in cardiomyocytes.

\section{Basal calcium handling is not affected by miR-221/222 in neoCM}

To analyse a possible effect of miR-221/222 on spontaneous calcium transients and beating activity, the next experiments were performed with murine neoCM. In our hands HL-1 cells do not show spontaneous beating activity. They also do not react to ISO, probably due to the fact that they are cultured with noradrenaline. In contrast, neoCM form functional spontaneously beating cell clusters after a few days in culture. Figure 3A shows that these clusters do not only contain CMs but also cardiac fibroblasts. This direct co-culture imitates the physiological in vivo situation more closely.

To investigate whether miR-221/222 influence basal calcium handling in neoCM, calcium transients were measured under control conditions for $2 \mathrm{~min}$. Both spontaneous calcium transients and electrically evoked transients were recorded. Monotonic transient analysis was performed using IonWizard software (IonOptix) to evaluate transient parameters for the baseline, departure, peak and return phases of the calcium transients (Fig. 3B). The baseline is defined as the fluorescence ratio at the beginning of the transient $\left(\mathrm{T}_{0}\right)$. The departure velocity (dep v) describes the speed of the increase in intracellular $\mathrm{Ca}^{2+}$. It is calculated as the maximum rate of change in fluorescence ratio during the departure phase. The time to maximum departure velocity (dep $v \mathrm{t}$ ) is defined as the time interval between $T_{0}$ and the maximum dep v. The peak is the maximum fluorescence ratio during the transient. The peak height is the difference between baseline and peak, i.e., the amplitude of the transient. The parameter baseline\%peak height describes the peak amplitude as percent change of basal calcium levels in the cells. The parameters for the return phase, return velocity (ret v) and time of maximum return velocity (ret $\mathrm{v} t$ ), are calculated like the ones for the departure phase.

Under unstimulated conditions there was no statistically significant difference in calcium transient parameters between miR-221/222 and mimic control (Fig. 3C-K). The high variability observed especially in the mc group is due to differences between the neonatal cardiomyocyte preparations. Two out of five monolayers showed higher values than the rest especially 


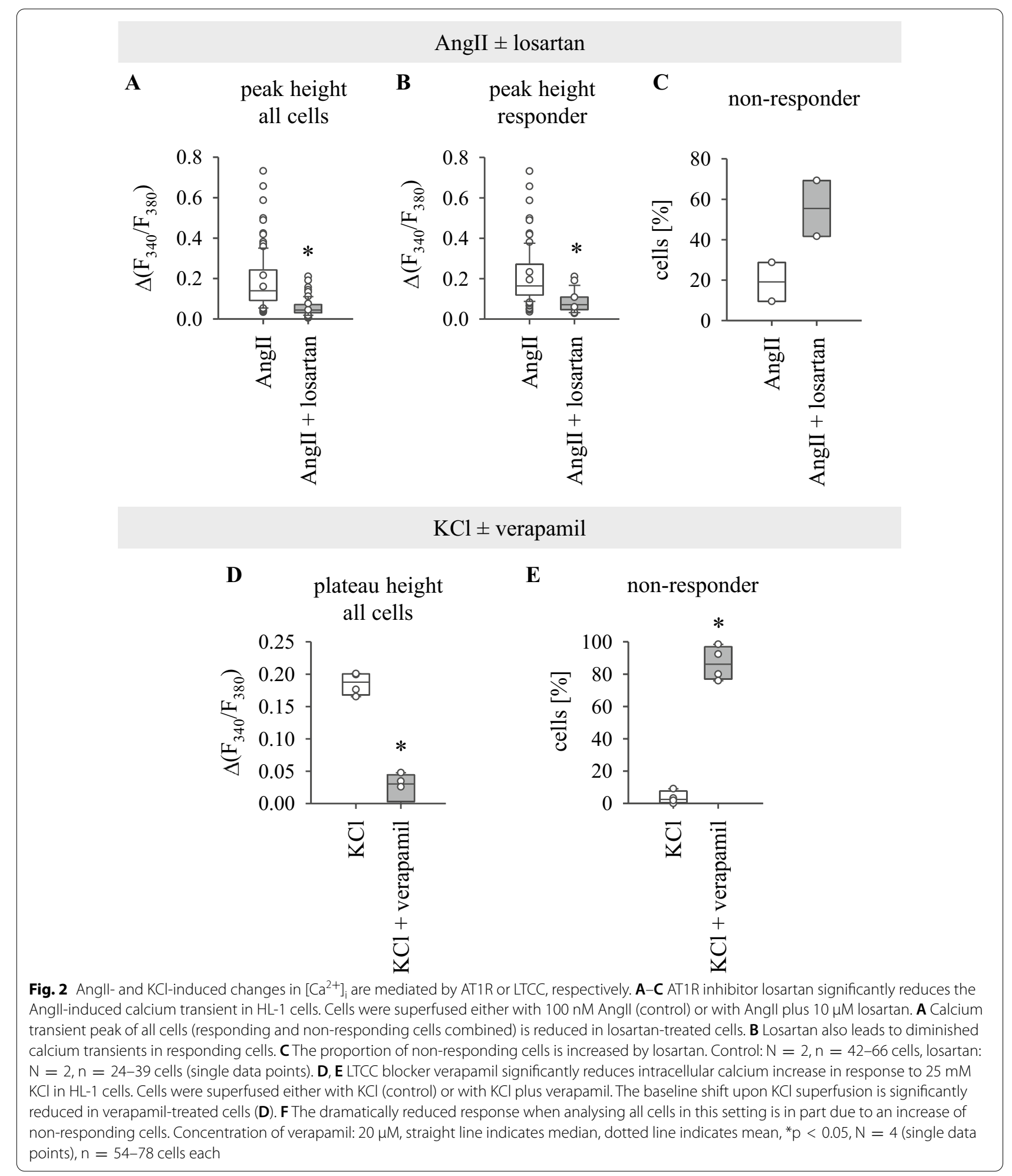


for departure velocity, peak height and return velocity. However, they also responded to ISO like the other monolayers.

\section{The effect of ISO on calcium transients is lost in miR-222-transfected neoCM}

To compare cellular responses in miR-221-, miR-222or mimic control-transfected neoCM monolayers, cells were stimulated with ISO to elicit an activating effect on LTCC and calcium-induced calcium release (CICR). Figure 4 shows the ISO effect in mimic control-, miR-221and miR-222-transfected monolayers. Due to variability of calcium transients between different neoCM preparations, transient characteristics under ISO were directly compared to the respective control. For this, the ISO effect was calculated as follows: mean transient parameter (ISO)/mean transient parameter (control). Therefore, data are represented as $\mathrm{x}$-fold change of control.

The results show that mimic control-transfected neoCM monolayers react to ISO (Fig. 4A). Exposure to $10 \mu \mathrm{M}$ ISO for in total 5-9 min significantly increased baseline fluorescence (Fig. 4D). As expected, departure velocity of the calcium transients was elevated as well (Fig. 4E). The time of maximal departure velocity (dep v t, Fig. 4F) was slightly, but not significantly reduced. Peak and peak height of the calcium transients were elevated as well (Fig. 4G, H). As mentioned above, the parameter baseline\%peak height describes the peak amplitude as percent change of basal calcium levels in the cells. In contrast to peak height, this parameter provides higher comparability of the ISO effect between samples. Accordingly, the ISO effect on baseline\%peak height is highly significant (Fig. 4I; $1.29 \pm 0.11$; p = 0.0292). While ISO slightly reduced time to peak, return velocity and time to reach maximal return velocity (Fig. 4J-L), these results did not reach statistical significance. All in all, there is a measurable ISO effect on departure velocity and peak amplitude in spontaneous or pacing-evoked calcium transients of mimic controltransfected neoCM monolayers. ISO application led to differential results in miR-transfected cells. While ISO evoked a response similar to $\mathrm{mc}$ in miR-221-transfected cells (Fig. 4B), virtually no effect of ISO could be detected in miR-222-transfected cells (Fig. 4C). Apart from return velocity, which is minimally increased, no parameter is significantly changed upon ISO addition in miR-222-transfected neoCM. Furthermore, there is a significant difference in the ISO effect between mc and miR-222 for the departure velocity, peak height and baseline\%peak height. Thus, the ISO effect observed in mc-transfected cells is lost in miR-222-transfected cells.

\section{The ISO-induced increase in spontaneous contraction frequency is abolished by miR-222}

After we established an impact of miR-221/222 on calcium entry and calcium transients due to depolarization or $\beta$-adrenergic stimulation, we wanted to know if miR-221/222 also affect cardiomyocyte beating frequency. Since miR-221 had no effect on calcium transients in neoCM, spontaneous contractions were only measured in miR-222-transfected neoCM and compared to mimic control. Occurrence of spontaneous beating was recorded for $30 \mathrm{~s}$ each under control conditions and after $10 \mu \mathrm{M}$ ISO addition. As expected, ISO induces an increase in spontaneous contraction frequency (positive chronotropic effect) in mimic control-transfected cells (Fig. 5, for analysed movies see Additional files $12,13,14)$. At $37^{\circ} \mathrm{C}$ the basal spontaneous beating frequency is $37.4 \pm 3.3$ beats per $30 \mathrm{~s}$ and it is increased to $71.7 \pm 8.5$ beats after addition of ISO (ISO1; Fig. 5C). There was no significant difference in spontaneous contraction frequency between mimic control and miR-222-treated neoCM under baseline conditions. However, the increase in spontaneous contraction frequency by ISO is strongly diminished in miR-222-transfected cells (Fig. 5, for analysed movies see Additional files 15, 16, 17). With miR-222, cells contracted $28.4 \pm 4.0$ times in $30 \mathrm{~s}$ and ISO addition led to an increase to only $40.8 \pm 7.1$ beats (ISO1). Since calcium measurements in HL-1 cells revealed that intracellular calcium increase was slowed in miR-transfected cells, the possibility of a delayed onset of ISO response was tested by including a second recording after ISO1 (ISO2). However, there was no change in beating frequency between both time points (ISO2: mc: $72.4 \pm 10$ beats/30 s vs. miR-222: $40.5 \pm 7.1$ beats/30 s).

(See figure on next page.)

Fig. 3 Calcium transient characteristics under control conditions are not affected by miR-221/222 in neoCM. A NeoCM form cell clusters with cardiac fibroblasts in culture. Immunofluorescence staining of ventricular neoCM after 6 days in culture. DAPI: nuclei, cardiac troponin T: cardiomyocytes, vimentin: fibroblasts. Scale bar indicates $50 \mu \mathrm{m}$. B Overview of most important monotonic transient analysis parameters calculated by lonWizard, sorted by the different phases of the transient. C-K Spontaneous or electrically evoked calcium transients were measured in monolayers under control conditions for $2 \mathrm{~min}$. Monotonic transient analysis was performed to evaluate transient parameters for the baseline (C), departure (D, E), peak $(\mathbf{F}-\mathbf{I})$ and return phases $(\mathbf{J}, \mathbf{K})$ of the calcium transients. There is no significant difference between miR-221/222 and mimic control (mc). Straight line indicates median, dotted line indicates mean, mc: $N=4-5$, miR-221: $N=6-7$, miR-222: $N=4$ 

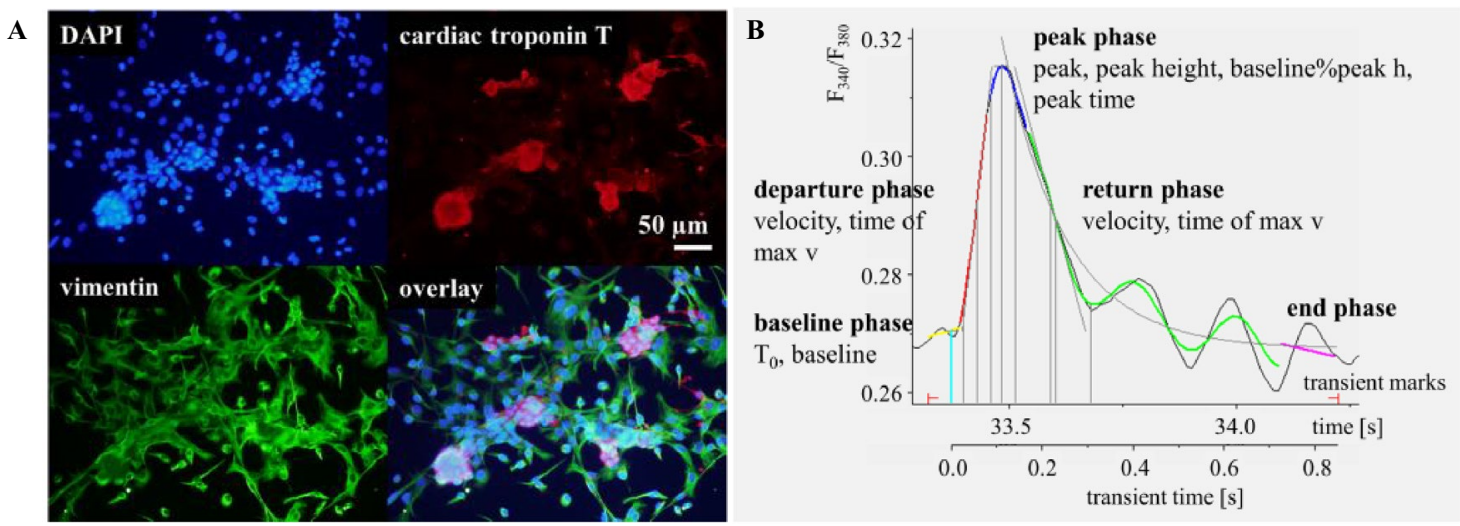

basal calcium transient characteristics
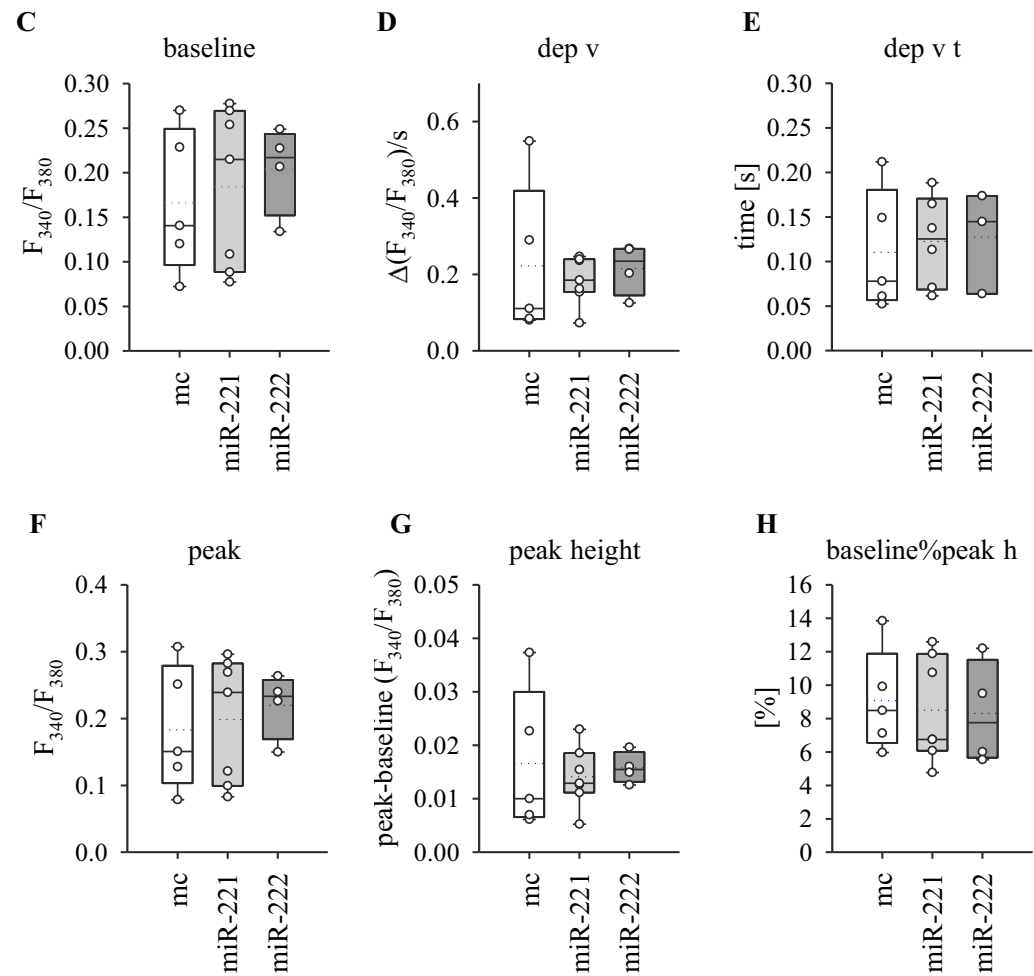

H
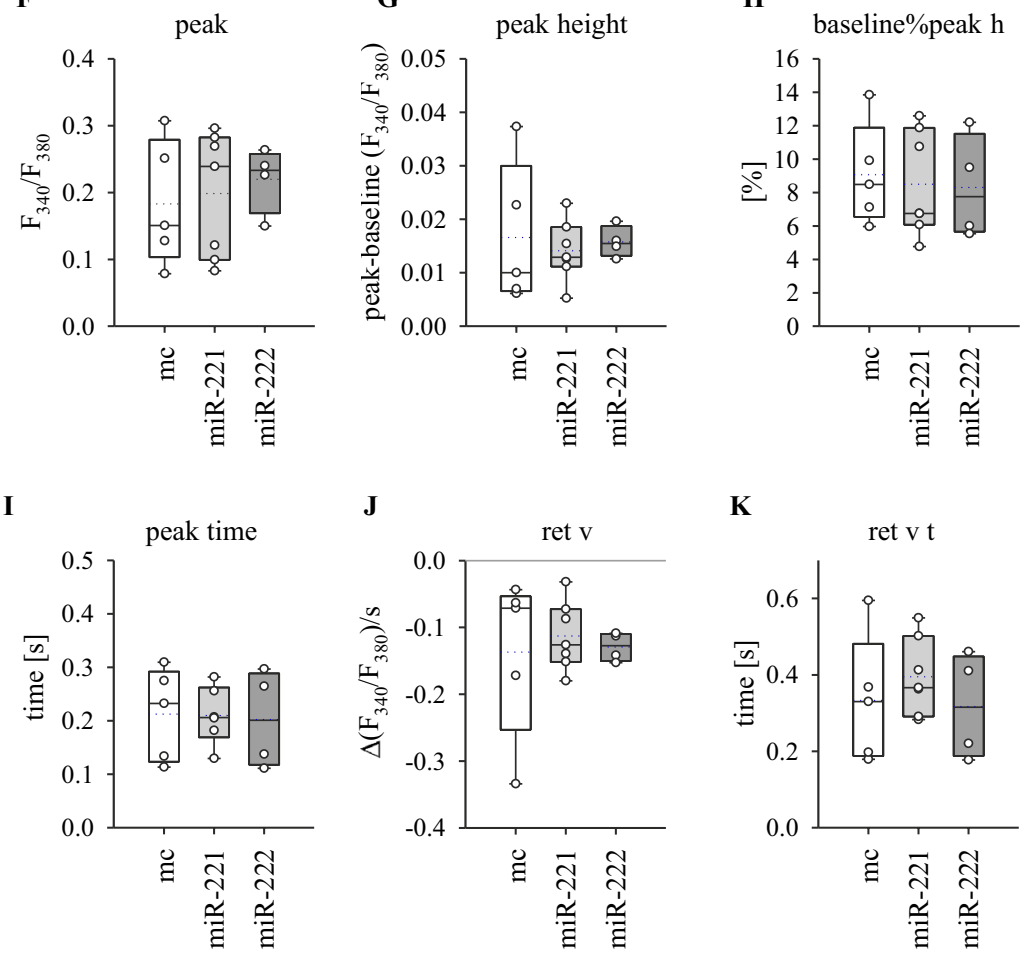

$\mathbf{K}$

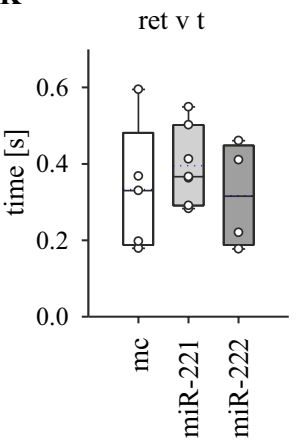

Fig. 3 (See legend on previous page.) 
average calcium transients \pm ISO
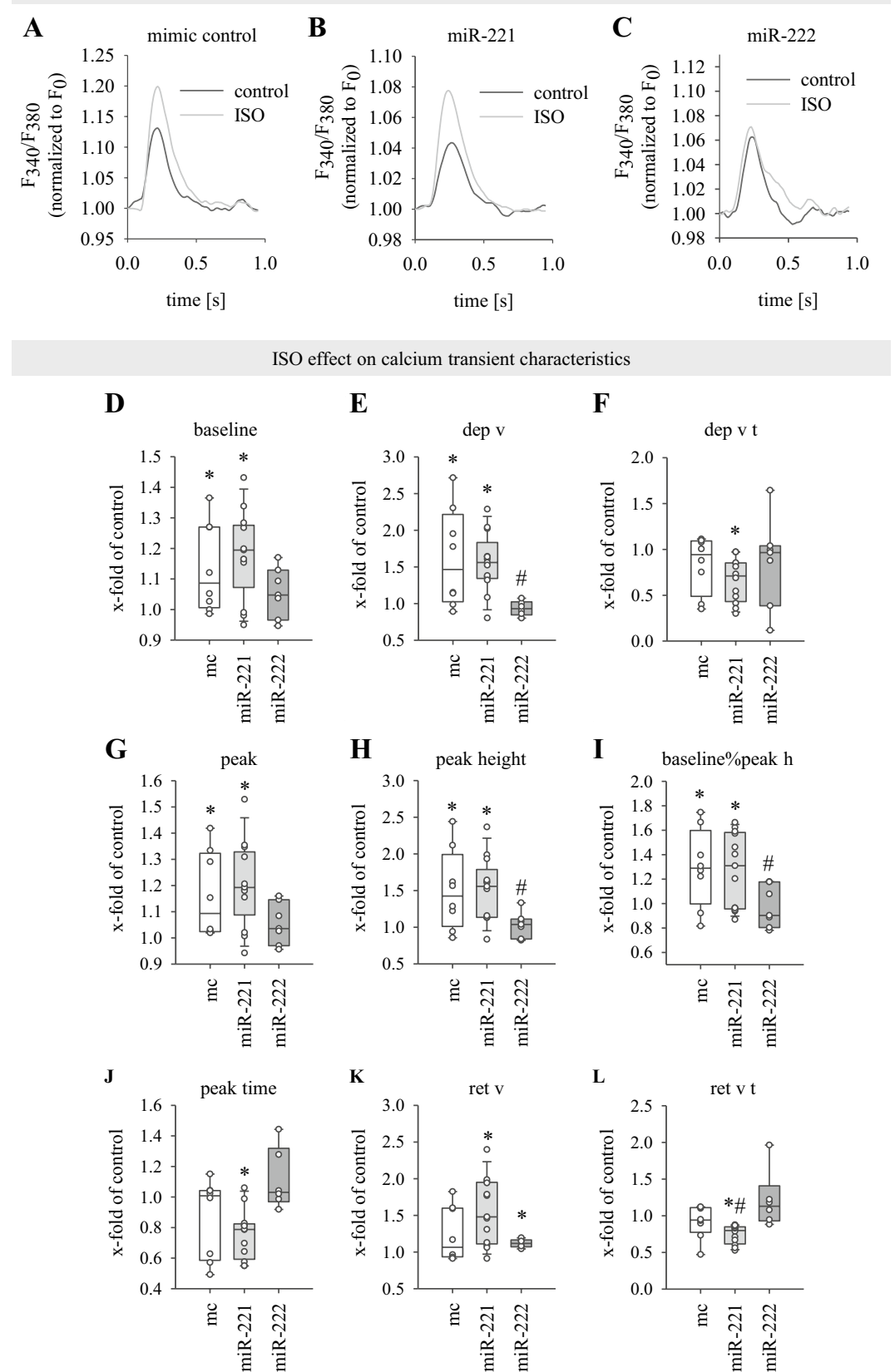

Fig. 4 The positive inotropic effect of ISO on $\left[\mathrm{Ca}^{2+}\right]_{\mathrm{i}}$ is lost in miR-222-transfected neoCM monolayers. A-C Average calcium transients show differential response to $10 \mu \mathrm{M}$ ISO in miR-222-transfected monolayers. Exemplary average transients are obtained from paced transients only (at least 5 transients) from one measurement each. Transients are representative for ISO effect on transient amplitude characteristics, not for baseline and kinetic parameters since data were normalized to fluorescence ratio at timepoint 0 (" $F_{0}{ }^{\prime \prime}$ ) and kinetic parameters vary slightly between measurements within one group. D-L Spontaneous or electrically evoked calcium transients were measured in monolayers under control conditions for $2 \mathrm{~min}$, and after ISO addition after further 2 and 6 min for 3 min each. Following monotonic transient analysis, the ISO effect was calculated as ratio of mean transient parameter under ISO exposure divided by mean transient parameter under control conditions for each monolayer. Therefore, data are shown as $x$-fold of control. For units of the shown parameters and absolute values under control conditions see Fig. 3. ISO effect is shown for parameters describing baseline (D), departure (E, F), peak $(\mathbf{G}-\mathbf{J})$ and return phase $(\mathbf{K}, \mathbf{L})$ of calcium transients. While ISO accelerates and enhances increase in cytosolic $\left[\mathrm{Ca}^{2+}\right]$ in neoCM transfected with mimic control and miR-221, this effect is lost in miR-222-transfected monolayers. Data are displayed as mean $\pm \mathrm{sem}$. Paired t test was used to directly compare the calcium transient parameters under control condition and after ISO application for each monolayer. ${ }^{*} \mathrm{p}<0.05 \mathrm{ISO}$ effect: ISO compared to respective control (no ISO = 1), $\# \mathrm{p}<0.05 \mathrm{ISO}$ effect in miR-transfected cells compared to ISO effect in mc-transfected cells. Straight line indicates median, dotted line indicates mean, $\mathrm{mc}: \mathrm{N}=8, \mathrm{miR}-221: \mathrm{N}=12-13, \mathrm{miR}-222: \mathrm{N}=6-7$ 


\section{Discussion}

miR-221/222 impair LTCC-induced calcium increase but not intracellular calcium release

Measurements of cytosolic calcium in HL-1 cells clearly showed that miR-221/222 reduce LTCC-mediated calcium increase due to significantly prolonged time to reach plateau calcium levels (miR-221/222) as well as significantly increased proportion of non-responding cells (miR-221). It is a limitation of this study that we did not measure a pure LTCC effect. Rather, we measured a combined effect of LTCC and SR. However, since we previously showed that miR-221/222 directly target LTCC subunit mRNAs and reduce LTCC current density in HL-1 cells [22] and cardiomyocytes depend on the entry of extracellular calcium for excitation-contraction coupling, this experiment still shows an effect on the LTCC.

In contrast to the response to $\mathrm{KCl}$, AngII-induced calcium transients were unaffected by miR-221/222. Since AngII elicits the observed transient increase in cytosolic calcium through release from intracellular stores [28], it can be used to estimate the influence of miR-221/222 on SR calcium load. While miR-221/222 impair LTCC-dependent calcium entry, handling of intracellular stores does not seem to be affected. This supports the notion that the miR-effect is mainly due to LTCC regulation. Because the effect of AngII on calcium release is independent of LTCC and there was no difference in response between miRs and control, we concluded that SR calcium load per se is not affected by miR-221/222. Of course, this is only an indirect measure and does not exclude an effect of miR-221/222 on the RyR. To study SR calcium load in more detail, RyR and SERCA2a function could be analysed in future experiments, using caffeine to activate RyR2 and thapsigargin to block SERCA2a.

All in all, miR-221/222 affect the depolarizationdependent LTCC-initiated intracellular calcium increase in $\mathrm{HL}-1$ cells. This could influence action potential generation, propagation and excitation-contraction coupling in cardiomyocytes in the heart.
miR-222 abolishes the ISO-induced inotropic effect on intracellular calcium transients in neoCM

As expected, ISO had a positive inotropic effect on intracellular calcium transients in neoCM. With miR-222, this ISO effect was completely gone. This is in good agreement with our previous results from luciferase assay [22], calcium measurements in HL-1 cells and also patch clamp measurements [22] showing that LTCC subunits are targets of miR-222.

But, in contrast to miR-222, there was no alteration of the ISO effect in miR-221 transfected neoCM. However, calcium measurements and also patch clamp in HL-1 cells showed an influence of miR-221 on LTCC-dependent calcium handling. This discrepancy can be explained by the different methods and thereby the different readouts. Intracellular calcium in HL-1 cells was measured after application of $\mathrm{KCl}$ until a clear plateau phase was observed, for $300 \mathrm{~s}$ in total. In this case, there was maximum activation of LTCC channels. Similar to this, $\mathrm{I}_{\mathrm{Ca}, \mathrm{L}}$ current was also measured at maximum activation of LTCC channels, so the impact of miR-221/222 on peak calcium current was analyzed. In contrast to these measurements, in neoCM no maximum activation but rather the more dynamic calcium handling important for excitation-contraction coupling was analyzed. NeoCM were paced at $1 \mathrm{~Hz}$ if there was no spontaneous activity, so calcium cycling had to be much faster and there probably was no maximum activation. This suggests that the miR221 effect might only be seen at maximum activation. However, since the results from neoCM dynamic calcium handling are functionally more relevant to the in vivo situation, miR-222 seems to be more important than miR221 in regulating $\mathrm{LTCC}$.

There are some limitations with calcium measurements in neoCM. Although a pre-plating step was added during isolation to reduce the number of non-cardiomyocytes, neoCM monolayers are not only cardiomyocytes [29] (see also Fig. 3A). Since neoCM need a few days after preparation to fully regain their properties and then have to be transiently transfected, measurements could be performed only after about seven days in culture. At this point, there was a considerable number of non-cardiomyocytes in the neoCM culture, even under culture

\footnotetext{
(See figure on next page.)

Fig. 5 The positive chronotropic effect of ISO is significantly reduced in miR-222-transfected neoCM. Spontaneous contraction activity was recorded at $37^{\circ} \mathrm{C}$ for $30 \mathrm{~s}$ each. ISO1 was measured 2 min after buffer change to ISO and ISO2 was measured 1.5 min after ISO1 (for exact timeline, see Methods section). A Representative contraction tracings are shown for mimic control and miR-222 for $10 \mathrm{~s}$ each (a.u.: arbitrary units). Corresponding movies and ROI overviews can be found in the Additional material (Additional files 4, 5, 6, 7, 8, 9, 10, 11, 12, 13, 14, 15, 16, 17). B Exemplary section of an ROI overview image of a neoCM monolayer (mc). Shown are three manually placed ROls (yellow circles), scale bar: 50 um. CWhile the number of spontaneous contractions was almost doubled in mc-transfected cells upon ISO application, this ISO effect is significantly reduced in miR-222-transfected cells. There is no difference between both ISO time points within each group. Data include 3 independent experiments, $\mathrm{N}=11$ petri dishes, $\mathrm{n}=5-37$ cells or cell clusters, depending on size of clusters or confluence of monolayer. Data are displayed as mean \pm sem, single data points represent the mean from each petri dish, ${ }^{*} \mathrm{p}<0.05$ respective to mc or corresponding control conditions as indicated
} 
$\mathbf{A}$

me
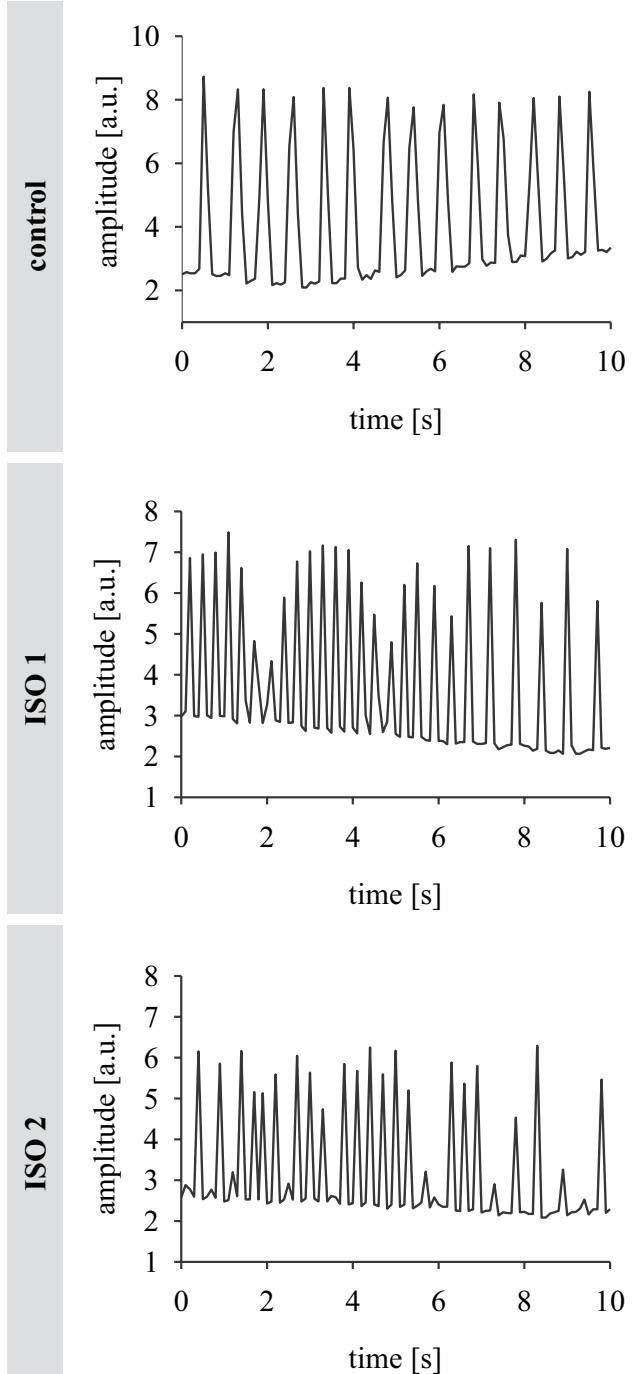

B

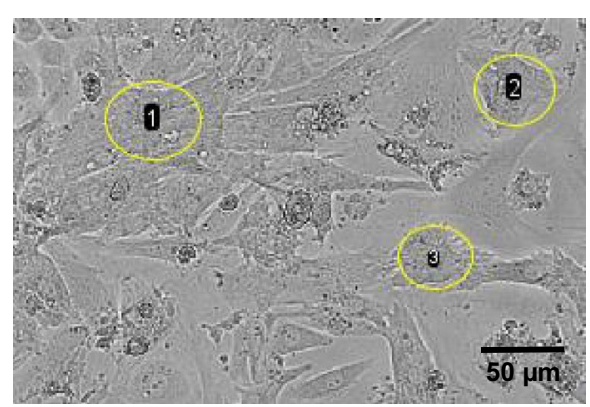

miR-222
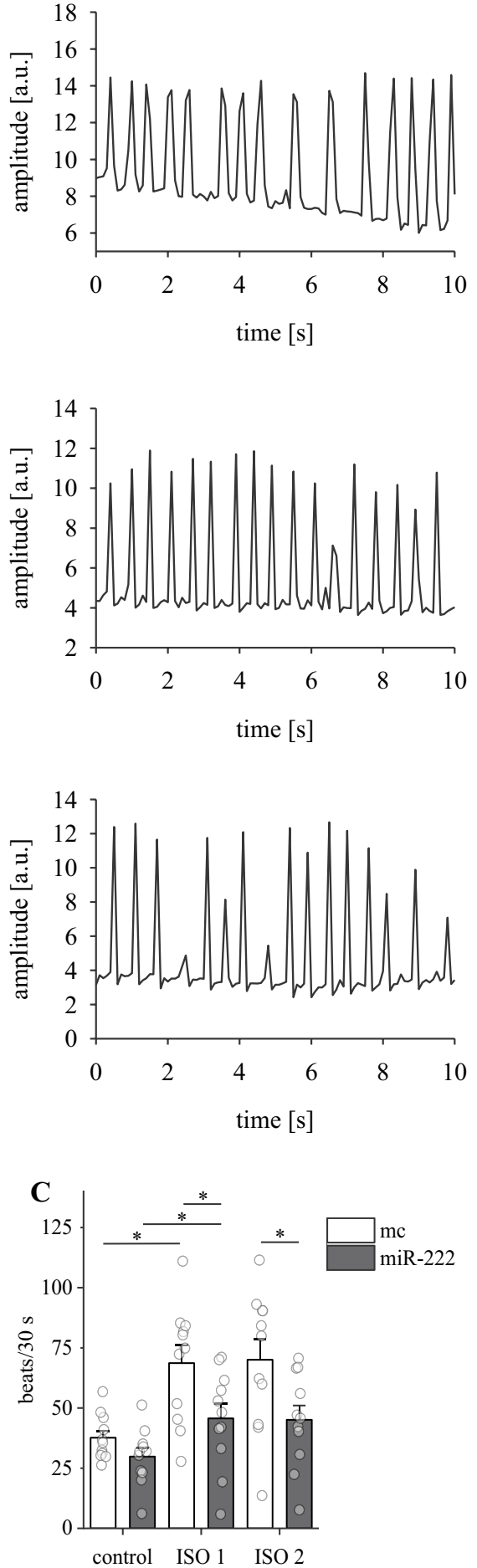

Fig. 5 (See legend on previous page.) 
conditions with only $1 \%$ FCS. So, it cannot be excluded that measured effects are also due to interaction of miRtransfected fibroblasts or endothelial cells with cardiomyocytes. Additionally, there is likely an underestimation of the miR effect because probably not all cells in the monolayer are transfected and cells are still proliferating after transfection, thereby further diluting the proportion of transfected cells and the observable miR effect. Also, a difference in the effects of miR-221/222 between neonatal and adult cardiomyocytes cannot be excluded.

\section{The ISO-induced increase in spontaneous contraction frequency is abolished by miR-222}

$\mathrm{NeoCM}$ react to ISO not only with faster and higher calcium transients, they also increase their spontaneous beating activity, thus implementing a positive chronotropic response. MiR-222 did not only influence the effect of ISO on calcium transients but also on spontaneous beating frequency in neoCM. While basal spontaneous contraction activity was similar in control and miR-222-transfected neoCM, the response to ISO was significantly reduced. This suggests reduced $\beta$-adrenergic responsiveness in miR-222-transfected cells which is an important feature of CMs in HF [27]. Since miR-221 had no effect on the ISO response regarding the calcium transients, it was not further analysed. The effect of miR-222 is probably due to regulating LTCC expression, as it is known that verapamil blocks spontaneous calcium transients [30] and contractions (Fig. 5, Additional file 1: Figure S1; movies: Additional files 2, 3).

In contrast to calcium measurements, contractions were recorded in unstained neoCM monolayers with brightfield illumination, so there was no problem with dye loading or photobleaching. Increasing the bath temperature of the neoCMs from room temperature to $34-37^{\circ} \mathrm{C}$ improved their spontaneous beating activity. Previous calcium measurements were performed at room temperature and often there was no spontaneous activity so that calcium transients had to be evoked electrically. Again, there likely is an underestimation of the miR effect due to transfection of probably only a portion of cells and further proliferation of neoCMs until the measurement.

\section{Possible influence of reduced LTCC protein expression on calcium homeostasis in the heart}

Since the LTCC is essential for action potential conduction and excitation-contraction coupling throughout the heart, a reduction in functional channel density could greatly impair cardiac function. MiR$221 / 222$ transfection led to several alterations in calcium handling in HL-1 cells and neoCM that would impact the whole heart. First, under unstimulated conditions, $\mathrm{KCl}$-induced $\mathrm{Ca}^{2+}$ entry was slowed and reduced in miR-transfected HL-1 cells compared to mimic control. This implies that basal LTCC activity is reduced in these cells, most likely due to posttranscriptional downregulation by miR-221/222 . In the present study the previously reported direct interaction of miR-221/222 with Cacna1c mRNA, which encodes the Cav1.2 pore forming subunit, was associated with a reduction in channel function. Furthermore, the effect of miR-221/222 on L-type $\mathrm{Ca}^{2+}$ current $\left(\mathrm{I}_{\mathrm{Ca}, \mathrm{L}}\right)$ density was analyzed by whole cell patch clamp recording [22]. It has been reported that HL-1 cells express several voltage-gated $\mathrm{Ca}^{2+}$ channels. Apart from LTCCs, of which Cav1.2 is higher expressed and mostly localized on the cell surface while Cav1.3 is lowly expressed and mostly located intracellularly, they also express $\mathrm{T}$-type $\mathrm{Ca}^{2+}$ channels (TTCC) [31]. To ensure that the observed $\mathrm{Ca}^{2+}$ current was mediated by LTCC and not TTCC, $\mathrm{I}_{\mathrm{Ca}, \mathrm{L}}$ was elicited at $-40 \mathrm{mV}$ which is too low for TTCC activation [31]. TTCCs activate at around $-70 \mathrm{mV}$ [31]. Transfection with mimics for both miRs decreased $\mathrm{I}_{\mathrm{Ca}, \mathrm{L}}$ density in HL-1 cells significantly, however, the voltage-dependence of activation was not altered [22]. Thus, the downregulation of peak $\mathrm{I}_{\mathrm{Ca}, \mathrm{L}}$ seems to be mainly due to transcriptional regulation of LTCC subunit mRNAs by miR-221/222.

The second observation was that $\beta$-adrenergic stimulation with ISO resulted in a reduced calcium transient amplitude in neoCM monolayers transfected with miR222 compared to mimic control. This suggests a reduced positive inotropic effect of ISO due to miR-222. Since contractility per se was not measured, the effect of miR$221 / 222$ on inotropy can only be discussed insofar as the calcium transient amplitude is thought to correlate with force development [32]. However, an inadequate response to $\beta$-adrenergic stimulation impairs the ability of the heart to adapt the cardiac output to differing needs and thus impairs cardiac function. This is in line with the observation that the $\beta$-adrenergic reserve is reduced in HF [33].

This also fits well to the third observation, that $\beta$-adrenergic stimulation resulted in a reduced positive chronotropic response in miR-222-transfected neoCM compared to mimic control. Ventricular neoCM exhibit spontaneous beating activity because they still express HCN channels $\left(\mathrm{I}_{\mathrm{f}}\right)$, TTCC and Cav1.3 as well as other components of the $\mathrm{Ca}^{2+}$ clock [34]. They express less TTCC than LTCC and the t-tubules are still in development but CICR, RyR, SERCA and SR calcium buffering are present [34]. In the heart the positive chronotropic effect of ISO is mediated by sinoatrial node (SAN), 
atrioventricular node (AVN) and conduction within the myocardium.

Transferring these results to the whole heart could mean that either pacemaking frequency is still increased due to ISO but conduction to or within the myocardium is slowed or that pacemaking frequency itself cannot adapt to ISO. Since SAN and AVN cells express mainly Cav1.3 and not Cav1.2 and until now we do not know whether miR-221/222 target also Cav1.3, heart rate may not be altered under control conditions. However, the most problematic result would be that the $\mathrm{Ca}^{2+}$ entry and therefore the contractility of the working myocardium in atria and ventricles is reduced under $\beta$-adrenergic stimulation because they express mainly Cav1.2 (atria also Cav1.3). The reduced cardiac function would lead to an elevated $\beta$-adrenergic tone but together with the reduced responsiveness to catecholamines this initiates and reinforces a vicious circle that in the end leads to failing of the heart [27]. Further experiments are necessary to determine the role of miR$221 / 222$ on contractility of neoCM.

That basal calcium transients as well as spontaneous beating frequency were not affected by the miRs could be explained by a certain buffering in LTCC biosynthesis as described by Rosati et al. [35]. If this was the case, LTCC expression may be reduced by miR-222, but would still be sufficient to ensure spontaneous activity under basal conditions. However, then the $\beta$-adrenergic reserve would be too low to allow for adequate increase in intracellular $\mathrm{Ca}^{2+}$ transient amplitude with ISO. In contrast to patch clamp and $\mathrm{KCl}$ where peak current and maximum $\mathrm{Ca}^{2+}$ entry were measured, spontaneous contractions under unstimulated conditions should not require maximal activation of all LTCCs present and thus even reduced LTCC expression should be sufficient. An alternative explanation would be that LTCC expression is reduced to a greater extent by miR-221/222 and that the fewer channels are in a more active state even under control conditions. In this case, ISO-induced PKA-dependent phosphorylation of LTCC could not increase LTCC activity and thus beating frequency any further.

\section{Role of miR-221/222 in cardiac disease}

MiR-221/222 are frequently upregulated in cardiac disease $[5,7-10,36,37]$ and seem to be associated with cardiac remodeling. Two studies with cardiac-specific overexpression of miR-221 or miR-222 in mice demonstrated cardiac hypertrophy and HF following miR overexpression $[12,13]$. This confirmed findings from other studies linking miR-221 and especially miR-222 to cardiac hypertrophy [5, 6]. Although cardiac hypertrophy is thought to arise due to increased $\mathrm{Ca}^{2+}$ entry or $\left[\mathrm{Ca}^{2+}\right]_{\mathrm{i}}$
[38], there is also evidence for the opposite situation. Mice with cardiac-specific heterozygous Cav1.2 deletion developed even more pronounced cardiac hypertrophy under $\beta$-adrenergic activation and reduced ventricular function than control mice [25]. In contrast to the two studies of $\mathrm{Su}$ et al. miR-221 and especially miR-222 have been shown to be more cardioprotective than detrimental, so the question arises whether a reduction of LTCC expression is beneficial. In fact, studies with LTCC inhibitors point in this direction. Benidipine inhibited cardiac hypertrophy and prevented HF in a mouse model with pressure overload [39] and diltiazem prevented disruption of $\mathrm{SR} \mathrm{Ca}^{2+}$ homeostasis in mice with hypertrophic cardiomyopathy [40]. Whether miR$221 / 222$ promote remodeling or protection may depend on the precise context of the respective cardiac disease. In the present study we could show that miR-221/222 impact the $\beta$-adrenergic response in cardiomyocytes by reducing LTCC function.

Nevertheless, it cannot be excluded that the observed miR-221/222 effect may also be partly mediated by the regulation of other putative targets. For example, RyR is also among the predicted targets of miR-221/222 and also downregulated in hearts of EGFR KO mice where miR-221/222 were upregulated [22]. Until now this putative target was not confirmed but its regulation would probably contribute to electrical remodeling, further reducing SR calcium load and thereby contractility.

\section{Differential effects of miR-221 and miR-222}

It seems that miR-222 elicits a stronger effect on LTCC in neoCM than miR-221, which is therefore also detectable even when LTCC is not maximally activated. While miR-221 also reduced peak $\mathrm{I}_{\mathrm{Ca}, \mathrm{L}}$ and slowed $\mathrm{KCl}$-induced increase in $\left[\mathrm{Ca}^{2+}\right]_{\mathrm{i}}$, it had no effect on the response to $\beta$-adrenergic stimulation, in contrast to miR-222. The $\beta$-subunit (Cacnb2) that enhances LTCC trafficking to the cell membrane is a confirmed target of miR-222 [41]. Loss of this subunit could, at least in part, explain the stronger effect of miR-222 on calcium handling in cardiomyocytes. It is also conceivable that miR-221 may additionally target regulators of $\mathrm{I}_{\mathrm{Ca}, \mathrm{L}}$ e.g., phosphatases, thereby contributing to preserved LTCC function. Differential targeting of miR-221/222 despite sharing the same seed sequence has been described before [42]. There is evidence that also the central and 3'-region of the miR may be important for target binding [42]. Additionally, miR-222 was lower expressed than miR-221 in hearts from WT and EGFR KO mice [22]. This suggests independent transcription [43] or posttranscriptional regulation of miR transcripts [44] which could further strengthen differential effects of miR-221 and -222 . 


\section{Conclusion}

This study adds a new role of miR-221/222 in cardiomyocytes by showing the impact on $\beta$-adrenergic regulation of LTCC function, calcium handling and beating frequency. Together with the previous report that miR-221/222 reduce GIRK1/4 function and LTCC current density, it expands our knowledge about the role of these miRs on cardiac ion channel regulation. Future studies in neoCM over a prolonged time or in mouse models are necessary to uncover potential miR221/222-induced compensatory mechanisms caused by reduced LTCC function and their effect on long-term cardiac remodeling and function.

\section{Materials and methods}

More detailed descriptions of neoCM isolation, calcium measurements and contraction analysis can be found in the supplemental information (Additional file 1).

\section{Ethics statement}

All mouse experiments described in this manuscript were performed according to the guidelines of the directive 2010/63/EU of the European Parliament on the protection of animals used for scientific purposes.

\section{Mouse models}

Wildtype C57BL/6 J mice were kept in the facilities of the University of Halle-Wittenberg at a room temperature of $20 \pm 1^{\circ} \mathrm{C}$, with a $12 \mathrm{~h} / 12 \mathrm{~h}$ light/dark cycle and were fed ad libitum with standard chow.

\section{Isolation and culture of neoCM and cardiac fibroblasts}

A detailed description can be found in the supplemental information (Additional file 1). In brief, neoCM were isolated from wildtype C57BL/6 J newborn mice on postnatal day $0-2$. Mice were sacrificed by decapitation and hearts were removed and placed in cold $0.9 \% \mathrm{NaCl}$ solution. Whole hearts were digested in $10 \mathrm{~min}$ steps using digestion buffer (HBSS, $0.5 \mathrm{mg} / \mathrm{ml}$ trypsin, $20 \mu \mathrm{g} /$ $\mathrm{ml}$ DNase II). Isolated cells were resuspended in neoCM medium (DMEM with $4.5 \mathrm{~g} / \mathrm{l}$ glucose, 5\% FCS, $20 \mu \mathrm{g} /$ $\mathrm{ml}$ vitamin $B_{12}$ ) supplemented with $25 \mu \mathrm{l} / \mathrm{ml}$ penicillin/ streptomycin. After the initial seeding the FCS content was reduced to $1 \%$ to minimize fibroblast growth.

\section{Cell culture}

All cells were cultured at $37^{\circ} \mathrm{C}$ and $5 \% \mathrm{CO}_{2}$. HL-1 cells were maintained in Claycomb medium with the following supplements: $10 \% \mathrm{FCS}, 2 \mathrm{mM} \mathrm{L}$-glutamine, $100 \mu \mathrm{M}$ noradrenaline, $100 \mathrm{U} / \mathrm{ml}$ penicillin and $100 \mu \mathrm{g} / \mathrm{ml}$ streptomycin. Cells were subcultured at confluency (once a week; $1 / 10$ ) and medium was changed twice a week.

\section{Transient transfection with miR-221/222 mimics}

For transient transfection of cells with miR-221/222 miRCURY LNA microRNA mimics (Qiagen, Venlo, Netherlands) without labels were used. HL-1 cells were transiently transfected with $30 \mathrm{nM}$ of miRCURY LNA miR-221/222 mimics or mimic negative control using $5 \mu$ l lipofectamine 2000 (Thermo Fisher Scientific, Waltham, Massachusetts, USA) in $1.5 \mathrm{ml}$ DMEM (Biochrom; without FCS) following manufacturer's instructions. After $24 \mathrm{~h}$ the medium was changed and cells were kept on Claycomb medium with supplements for further $48 \mathrm{~h}$. NeoCM were transiently transfected like HL-1 cells. After $24 \mathrm{~h}$ the medium was changed and cells were kept on DMEM with $4.5 \mathrm{~g} / \mathrm{l}$ glucose, $20 \mu \mathrm{g} / \mathrm{ml}$ vitamin $B_{12}$ and $5 \%$ FCS for further $48 \mathrm{~h}$.

\section{Calcium imaging in $\mathrm{HL}-1$ cells}

Calcium homeostasis in HL-1 cells was measured by ratiometric fluorescence microscopy using Fura-2 AM. HL-1 cells were plated on FCS-coated custommade glass coverslips for $24 \mathrm{~h}$ in Claycomb medium with supplements. MiR-transfected HL-1 cells were loaded with $4 \mu \mathrm{M}$ Fura-2 AM (stock solution: $1 \mathrm{mM}$ in DMSO) at $37^{\circ} \mathrm{C}$ for $30 \mathrm{~min}$. During the experiment cells were superfused with pre-warmed control and test solutions (temperature when reaching the cells: $37^{\circ} \mathrm{C}$ ). Ringer buffer (control solution) contained in $\mathrm{mM}: \mathrm{NaCl}$ 122.5, $\mathrm{KCl} 5.4, \mathrm{MgCl}_{2} \times 6 \mathrm{H}_{2} \mathrm{O} 0.8, \mathrm{CaCl}_{2} \times 2 \mathrm{H}_{2} \mathrm{O} \mathrm{1.2,}$ $\mathrm{NaH}_{2} \mathrm{PO}_{4} \times \mathrm{H}_{2} \mathrm{O}$ 1.0, glucose 5.5, HEPES 10; $\mathrm{pH}$ was adjusted to 7.4 at $37^{\circ} \mathrm{C}$. The measurement started with control solution for $200-300 \mathrm{~s}$ to get a stable baseline signal, followed by superfusion with $100 \mathrm{nM}$ AngII for $150 \mathrm{~s}$ to observe a transient $\left[\mathrm{Ca}^{2+}\right]_{\mathrm{i}}$ increase. After this, control Ringer solution was applied for $150 \mathrm{~s}$ to wash out AngII. To depolarize the cell membrane and activate LTCCs, the next step included Ringer solution with $25 \mathrm{mM} \mathrm{KCl}$ (instead of $5 \mathrm{mM}$ in control solution) for $300 \mathrm{~s}$. In a last step, cells were superfused with $1 \mu \mathrm{M}$ ionomycin which serves as a positive control to discriminate between non-responding and dead cells. To test whether AngII and $25 \mathrm{mM} \mathrm{KCl}$ elicit the expected specific effects, inhibitors of AngII receptor type 1 (AT1R) (losartan, $10 \mu \mathrm{M}$ ) and LTCC (verapamil, $20 \mu \mathrm{M}$ ) were applied in additional experiments. Images of Fura-2 fluorescence intensity at excitation wavelengths of $340 \mathrm{~nm}$ and $380 \mathrm{~nm}$ were obtained with VisiVIEW Imaging Software (Visitron Systems; exposure: $40 \mathrm{~ms}$, bin: 2, sampling interval: $2 \mathrm{~s}$, emission: $510 \mathrm{~nm}$ ). Analysis was performed on single cell level by defining one region of interest per cell. 340/380 ratios were exported to Excel. Background fluorescence was subtracted. The reaction of a cell to a substance was defined as a response if the maximum value was higher than the mean plus 
three times the standard deviation of the control solution before substance application [e.g., maximum value (AngII) > mean (Ringer) $+3 \times$ standard deviation (Ringer)]. First, values from dead cells were eliminated due to lack of response to ionomycin. Then, responding and non-responding cells were defined. Response parameters, e.g., baseline shift, peak height, AUC (AngII: $140 \mathrm{~s}$, KCl: first $150 \mathrm{~s}$ ), were only obtained from responding cells unless indicated otherwise.

\section{Calcium measurement in neoCM}

Calcium transients from spontaneous or electrically evoked activity in neoCM were obtained with the Myocyte Calcium and Contractility System (IonOptix, Westwood, Massachusetts, USA). NeoCM were measured 6-9 days after isolation. NeoCM monolayers were transiently transfected with miR mimics for $24 \mathrm{~h}$ as described above. Cells were loaded with $4 \mu \mathrm{M}$ Fura-2 AM (stock solution: $1 \mathrm{mM}$ in DMSO) at $37^{\circ} \mathrm{C}$ for $30 \mathrm{~min}$. Each sample was measured three times at room temperature: after recording control signals for $2 \mathrm{~min}$ the buffer was changed to $10 \mu \mathrm{M}$ isoprenaline (ISO) ( 2 min break) and response to ISO was measured for $3 \mathrm{~min}$ and after a $1 \mathrm{~min}$ break again for $3 \mathrm{~min}$. If possible, spontaneous calcium transients were recorded. Otherwise, cells were paced at $1 \mathrm{~Hz}$ to evoke calcium transients (MyoPacer, 5-10 V per pulse, pulse duration maximum $4 \mathrm{~ms}$ ). IonWizard 6.6 (IonOptix) was used for data acquisition at sampling frequencies of $100 \mathrm{~Hz}$ (average 4: 4 collected data points are averaged into one raw data point) or $250 \mathrm{~Hz}$ (average 1). Monotonic transient analysis was performed using IonWizard 6.6.

\section{Contraction analysis in neoCM}

NeoCM were isolated as described above and cells from about one heart were plated onto one $35 \mathrm{~mm}$ petri dish. Monolayers were transfected with mimic control or miR-222 as described above and measured after about 7-8 days in culture. Before the recording cells were washed with Ringer buffer once. Cells were then placed into a pre-heated Ibidi chamber (Ibidi heating system 1; plate temperature: $38^{\circ} \mathrm{C}$, lid: $42^{\circ} \mathrm{C}$; Ibidi, Gräfelfing, Germany) and allowed to acclimatize for $1 \mathrm{~min}$. Contraction recordings were performed as follows: acclimatization of the cells in Ringer for $60 \mathrm{~s}$, movie 1 (control) $30 \mathrm{~s}$, buffer change to $10 \mu \mathrm{M}$ ISO and acclimatization $150 \mathrm{~s}$, movie 2 (ISO 1) $30 \mathrm{~s}$, break $90 \mathrm{~s}$, movie 3 (ISO 2) $30 \mathrm{~s}$. Movies were analyzed using Myocyter [45] with the following parameters: "detection": 10 , "\% of $\max$ recognized as beat": 20 .

\section{Statistical analysis}

Data are presented as mean \pm standard error of mean. Student's t test, Mann-Whitney rank sum test or Wilcoxon signed rank test were used as applicable according to pre-test data analysis by SigmaPlot 12.5. Tests were unpaired and two-tailed unless stated otherwise in the text. Grubbs tests were performed to identify outliers. A p value $<0.05$ was considered statistically significant. Graphics were created using Sigmaplot 12.5 and Origin 2018.

\begin{abstract}
Abbreviations
$\left[\mathrm{Ca}^{2+}\right]_{i}$ : Intracellular calcium ion concentration; Angll: Angiotensin II; AT1 R: Angiotensin II receptor type 1; a.u.: Arbitrary units; AUC: Area under the curve; AVP: Atrioventricular node; baseline\%peak h: Peak height as percentage of baseline; Cacna1c: Calcium channel gene, voltage-dependent, $L$ type, alpha 1C subunit; Cacna2d1: Calcium channel gene, voltage-dependent, alpha2/delta subunit 1; Cacnb2: Calcium channel gene, voltage-dependent, beta 2 subunit; CAMP: Cyclic adenosine monophosphate; Cav1.2: L-type $\mathrm{Ca}^{2+}$ channel pore-forming subunit alpha 1C; Cav1.3: L-type $\mathrm{Ca}^{2+}$ channel pore-forming subunit alpha 1D; DAPI: 4',6-Diamidino-2-phenylindole; dep $\checkmark(\mathrm{t})$ : (Time of) maximal departure velocity; EGFR: Epidermal growth factor receptor; $F_{340} / F_{380}$ : Ratio of fluorescence intensities at $340 \mathrm{~nm}$ and $380 \mathrm{~nm}$ excitation wavelengths; Fps: Frames per second; HCN: Hyperpolarizationactivated cyclic nucleotide-gated channel; HF: Heart failure; I $\mathrm{Ca}_{\text {: }}$ : L-type $\mathrm{Ca}^{2+}$ current; IP3: Inositol 1,4,5-trisphosphate; ISO: Isoprenaline; KCl: Potassium chloride; KO: Knockout; LTCC: L-type $\mathrm{Ca}^{2+}$ channel; mc: Mimic control; miR: MicroRNA; neoCM: Neonatal cardiomyocytes; peak h: Peak height; peak t: Peak time (time to peak); ret $v$ (t): (Time of) maximal return velocity; ROI: Region of interest; SAN: Sinoatrial node; SERCA: Sarco/endoplasmic reticulum $\mathrm{Ca}^{2+}$ ATPase; SR: Sarcoplasmic reticulum; TTCC: T-type $\mathrm{Ca}^{2+}$ channel; WT: Wildtype; $\beta$-AR: $\beta$-Adrenergic receptor.
\end{abstract}

\section{Supplementary Information}

The online version contains supplementary material available at https://doi. org/10.1186/s13578-021-00676-4.

Additional file 1. Additional figure 1 (Contraction-inhibiting effect of verapamil depends on neoCM cluster size), list of supplemental movies and images, supplementary methods. Figure S1. Spontaneous beating activity at room temperature was measured under control conditions (for ca. $54 \mathrm{~s}$ ) and at two successive time periods after solution change to $10 \mu \mathrm{M}$ verapamil (verapamil 1: ca. $54 \mathrm{~s}$ movie, verapamil 2: ca. $58 \mathrm{~s}$ movie). Beats were analysed using Myocyter Image J plugin. A Cluster-specific beating activity. $\mathbf{B}$ Statistical analysis. $N=1, n=9$ cluster, paired t-test, ${ }^{*} p<0.05$. The corresponding movies can be found in the supplemental material.

Additional file 2: Figure S2. ROI overview: Untransfected neoCM spontaneous contraction control (for quantification see Additional file 1: Figure S1)

Additional file 3: Figure S3. ROI overview: Untransfected neoCM spontaneous contraction verapamil (for quantification see Additional file 1: Figure S1)

Additional file 4: Figure S4. ROI overview: mc-transfected neoCM spontaneous contraction control (for corresponding tracings of $\mathrm{ROI} 3$ see Fig. 5A).

Additional file 5: Figure S5. ROI overview: mc-transfected neoCM spontaneous contraction ISO 1 (for corresponding tracings of ROI 3 see Fig. 5A). 
Additional file 6: Figure S6. ROI overview: mc-transfected neoCM spontaneous contraction ISO 2 (for corresponding tracings of ROI 3 see Fig. 5A)

Additional file 7: Figure S7. ROl overview: miR-222-transfected neoCM spontaneous contraction control (for corresponding tracings of ROI 1 see Fig. 5A).

Additional file 8: Figure S8. ROl overview: miR-222-transfected neoCM spontaneous contraction ISO 1 (for corresponding tracings of ROI 1 see Fig. 5A).

Additional file 9: Figure S9. ROl overview: miR-222-transfected neoCM spontaneous contraction ISO 2 (for corresponding tracings of ROI 1 see Fig. 5A).

Additional file 10: Movie S1. Untransfected neoCM spontaneous contraction control (for quantification see Additional file 1: Figure S1).

Additional file 11: Movie S2. Untransfected neoCM spontaneous contraction verapamil (for quantification see Additional file 1: Figure S1).

Additional file 12: Movie S3. mc-transfected neoCM spontaneous contraction control (for corresponding tracings of ROI 3 see Fig. 5A).

Additional file 13: Movie S4. mc-transfected neoCM spontaneous contraction ISO 1 (for corresponding tracings of ROI 3 see Fig. 5A).

Additional file 14: Movie S5. mc-transfected neoCM spontaneous contraction ISO 2 (for corresponding tracings of ROI 3 see Fig. 5A).

Additional file 15: Movie S6. miR-222-transfected neoCM spontaneous contraction control (for corresponding tracings of ROI 1 see Fig. 5A).

Additional file 16: Movie S7. miR-222-transfected neoCM spontaneous contraction ISO 1 (for corresponding tracings of ROI 1 see Fig. 5A).

Additional file 17: Movie S8. miR-222-transfected neoCM spontaneous contraction ISO 2 (for corresponding tracings of ROI 1 see Fig. 5A).

\section{Acknowledgements}

Publication charges were funded by the Open Access Publication Fund of the Martin-Luther-University Halle-Wittenberg.

\section{Authors' contributions}

MK, SR and BS made substantial contributions to the acquisition of the work. CG, MG and BS made substantial contributions to the conception and the design of the work. MK, CG, MG and BS made substantial contributions to the analysis and interpretation of the data. MK drafted the manuscript and CG, MG and $B S$ revised it critically. CG, MG and BS were responsible for the financial support of the work. All authors read and approved the final manuscript.

\section{Funding}

Open Access funding enabled and organized by Projekt DEAL. This work was supported by the Deutsche Forschungsgemeinschaft (DFG) in the research training group "RTG1591 — Posttranscriptional Control of Gene Expression: Mechanisms and Role in Pathogenesis" and by the DFG-Grant GE905/19.

\section{Availability of data and materials}

Derived data supporting the findings of this study are available from the corresponding author $\mathrm{MK}$ on request.

\section{Code availability}

Not applicable.

\section{Declarations}

Ethics approval and consent to participate

Not applicable.

\section{Consent for publication}

Not applicable.

\section{Competing interests}

The authors declare that they have no competing interests.
Received: 11 May 2021 Accepted: 2 August 2021

Published online: 17 August 2021

\section{References}

1. Azevedo PS, Polegato BF, Minicucci MF, Paiva SAR, Zornoff LAM. Cardiac remodeling: concepts, clinical impact, pathophysiological mechanisms and pharmacologic treatment. Arq Bras Cardiol. 2016;106(1):62-9.

2. Aiba T, Tomaselli GF. Electrical remodeling in the failing heart. Curr Opin Cardiol. 2010;25(1):29-36.

3. Tang R, Long T, Lui KO, Chen Y, Huang ZP. A roadmap for fixing the heart: RNA regulatory networks in cardiac disease. Mol Ther Nucleic Acids. 2020;20:673-86. https://doi.org/10.1016/j.omtn.2020.04.007.

4. Song Q, An Q, Niu B, Lu X, Zhang N, Cao X. Role of miR-221/222 in tumor development and the underlying mechanism. J Oncol. 2019. https://doi. org/10.1155/2019/7252013.

5. Wang C, Wang S, Zhao P, Wang X, Wang J, Wang Y, et al. MiR-221 promotes cardiac hypertrophy in vitro through the modulation of p27 expression. J Cell Biochem. 2012;113(6):2040-6.

6. Liu X, Xiao J, Zhu H, Wei X, Platt C, Damilano F, et al. MiR-222 is necessary for exercise-induced cardiac growth and protects against pathological cardiac remodeling. Cell Metab. 2015;21(4):584-95.

7. Coskunpinar E, Cakmak HA, Kalkan AK, Tiryakioglu NO, Erturk M, Ongen Z. Circulating miR-221-3p as a novel marker for early prediction of acute myocardial infarction. Gene. 2016;591(1):90-6.

8. Kakimoto Y, Tanaka M, Hayashi H, Yokoyama K, Osawa M. Overexpression of miR-221 in sudden death with cardiac hypertrophy patients. Heliyon. 2018;4(6): e00639. https://doi.org/10.1016/j.heliyon.2018.e00639.

9. Huang D, Chen Z, Wang J, Chen Y, Liu D, Lin K. MicroRNA-221 is a potential biomarker of myocardial hypertrophy and fibrosis in hypertrophic obstructive cardiomyopathy. Biosci Rep. 2020;40(1):1-13.

10. Lok SI, De Jonge N, Van Kuik J, Van Geffen AJP, Huibers MMH, Van Der Weide $P$, et al. MicroRNA expression in myocardial tissue and plasma of patients with end-stage heart failure during LVAD support: comparison of continuous and pulsatile devices. PLoS ONE. 2015;10(10):1-13. https:// doi.org/10.1371/journal.pone.0136404.

11. Hromadnikova I, Kotlabova K, Dvorakova L, Krofta L. Diabetes mellitus and cardiovascular risk assessment in mothers with a history of gestational diabetes mellitus based on postpartal expression profile of micrornas associated with diabetes mellitus and cardiovascular and cerebrovascular diseases. Int J Mol Sci. 2020;21(7):1-46.

12. Su M, Wang J, Wang C, Wang X, Dong W, Qiu W, et al. MicroRNA-221 inhibits autophagy and promotes heart failure by modulating the p27/ CDK2/mTOR axis. Cell Death Differ. 2015;22(6):986-99.

13. Su M, Chen Z, Wang C, Song L, Zou Y, Zhang L, et al. Cardiac-specific overexpression of miR-222 induces heart failure and inhibits autophagy in mice. Cell Physiol Biochem. 2016;39(4):1503-11.

14. Schmitz B, Brand S-MSM. Commentary: microRNA-221/222 family counteracts myocardial fibrosis in pressure overload-induced heart failure. Front Cardiovasc Med. 2018:5:1-2.

15. Chen Q, Zhou Y, Richards AM, Wang P. Up-regulation of miRNA-221 inhibits hypoxia/reoxygenation-induced autophagy through the DDIT4/ mTORC1 and Tp53inp1/p62 pathways. Biochem Biophys Res Commun. 2016:474(1):168-74. https://doi.org/10.1016/j.bbrc.2016.04.090.

16. Corsten M, Heggermont W, Papageorgiou AP, Deckx S, Tijsma A, Verhesen $W$, et al. The microRNA-221/-222 cluster balances the antiviral and inflammatory response in viral myocarditis. Eur Heart J. 2015;36(42):2909-19.

17. Verjans $R$, Peters $T$, Beaumont FJ, Van Leeuwen $R$, Van Herwaarden $T$, Verhesen W, et al. MicroRNA-221/222 family counteracts myocardial fibrosis in pressure overload-induced heart failure. Hypertension. 2018;71(2):280-8

18. Tian Z, Miyata K, Kadomatsu T, Horiguchi H, Fukushima H, Tohyama S, et al. ANGPTL2 activity in cardiac pathologies accelerates heart failure by perturbing cardiac function and energy metabolism. Nat Commun. 2016. https://doi.org/10.1038/ncomms13016.

19. Vujic A, Lerchenmüller C, Di WuT, Guillermier C, Rabolli CP, Gonzalez $E$, et al. Exercise induces new cardiomyocyte generation in the adult 
mammalian heart. Nat Commun. 2018;9(1):1-9. https://doi.org/10.1038/ s41467-018-04083-1.

20. Sun L, Zhu W, Zhao P, Zhang J, Lu Y, Zhu Y, et al. Down-regulated exosomal microRNA-221 - $3 p$ derived from senescent mesenchymal stem cells impairs heart repair. Front Cell Dev Biol. 2020;8:1-14.

21. Lai TC, Lee TL, Chang YC, Chen YC, Lin SR, Lin SW, et al. MicroRNA-221/222 mediates ADSC-exosome-induced cardioprotection against ischemia/ reperfusion by targeting PUMA and ETS-1. Front Cell Dev Biol. 2020:8:1-17.

22. Binas S, Knyrim M, Hupfeld J, Kloeckner U, Rabe S, Mildenberger S, et al. miR-221 and -222 target CACNA1C and KCNJ5 leading to altered cardiac ion channel expression and current density. Cell Mol Life Sci. 2020;77(5):903-18. https://doi.org/10.1007/s00018-019-03217-y.

23. Davlouros PA, Gkizas V, Vogiatzi C, Giannopoulos G, Alexopoulos D, Deftereos S. Calcium homeostasis and kinetics in heart failure. Med Chem. 2016;12(2):151-61.

24. Cheng J, Cao J, Jiang X, Xu L, Wang Y. Kv4.3 expression reverses ICa remodeling in ventricular myocytes of heart failure. Oncotarget. 2017;8(61):104037-45.

25. Goonasekera SA, Hammer K, Auger-Messier M, Bodi I, Chen X, Zhang H, et al. Decreased cardiac L-type $\mathrm{Ca}^{2+}$ channel activity induces hypertrophy and heart failure in mice. J Clin Invest. 2012;122(1):280-90.

26. Striessnig J, Pinggera A, Kaur G, Bock G, Tuluc P. L-type Ca ${ }^{2+}$ channels in heart and brain. Wiley Interdiscip Rev Membr Transp Signal. 2014;3(2):15-38.

27. El-Armouche A, Eschenhangen T. $\beta$-Adrenergic stimulation and myocardial function in the failing heart. Hear Fail Rev. 2009;14:225-41.

28. Egger M, Domenighetti AA. Adaptive and maladaptive remodeling of cardiomyocyte excitation-contraction coupling by angiotensin II. Trends Cardiovasc Med. 2010;20(3):78-85. https://doi.org/10.1016/j.tcm.2010.06. 001.

29. Ehler E, Moore-Morris T, Lange S. Isolation and culture of neonatal mouse cardiomyocytes. J Vis Exp. 2013;79:1-10.

30. Li X, Shen L, Zhao F, Zou X, He Y, Zhang F, et al. Modification of distinct ion channels differentially modulates $\mathrm{Ca}^{2+}$ dynamics in primary cultured rat ventricular cardiomyocytes. Sci Rep. 2017;7:1-14.

31. Xia M, Salata JJ, Figueroa DJ, Lawlor AM, Liang HA, Liu Y, et al. Functional expression of L-and T-type $\mathrm{Ca}^{2+}$ channels in murine $\mathrm{HL}-1$ cells. J Mol Cell Cardiol. 2004;36(1):111-9.

32. Saleem U, Mannhardt I, Braren I, Denning C, Eschenhagen T, Hansen A. Force and calcium transients analysis in human engineered heart tissues reveals positive force-frequency relation at physiological frequency. Stem Cell Reports. 2020;14(2):312-24. https://doi.org/10.1016/j.stemcr.2019.12. 011.

33. Chen X, Piacentino V, Furukawa S, Goldman B, Margulies KB, Houser SR. $\mathrm{L}$-type $\mathrm{Ca}^{2+}$ channel density and regulation are altered in failing human ventricular myocytes and recover after support with mechanical assist devices. Circ Res. 2002;91(6):517-24.

34. Louch WE, Koivumäki JT, Tavi P. Calcium signalling in developing cardiomyocytes: implications for model systems and disease. J Physiol. 2015:593(5):1047-63.

35. Rosati B, Yan Q, Lee MS, Liou SR, Ingalls B, Foell J, et al. Robust L-type calcium current expression following heterozygous knockout of the Cav1.2 gene in adult mouse heart. J Physiol. 2011;589(13):3275-88.

36. Sayed D, Hong C, Chen IY, Lypowy J, Abdellatif M. MicroRNAs play an essential role in the development of cardiac hypertrophy. Circ Res. 2007;100(3):416-24.

37. Tatsuguchi M, Seok HY, Callis TE, Thomson JM, Chen JF, Newman M, et al. Expression of microRNAs is dynamically regulated during cardiomyocyte hypertrophy. J Mol Cell Cardiol. 2007;42(6):1137-41.

38. Chen X, Nakayama H, Zhang X, Ai X, Harris DM, Tang M, et al. Calcium influx through Cav1.2 is a proximal signal for pathological cardiomyocyte hypertrophy. J Mol Cell Cardiol. 2011;50(3):460-70. https://doi.org/10. 1016/j.yjmcc.2010.11.012.

39. Liao Y, Asakura M, Takashima S, Ogai A, Asano Y, Asanuma H, et al. Benidipine, a long-acting calcium channel blocker, inhibits cardiac remodeling in pressure-overloaded mice. Cardiovasc Res. 2005;65(4):879-88.

40. Semsarian C, Ahmad I, Giewat M, Georgakopoulos D, Schmitt JP, McConnell BK, et al. The L-type calcium channel inhibitor diltiazem prevents cardiomyopathy in a mouse model. J Clin Invest. 2002;109(8):1013-20.

41. Carrillo ED, Escobar Y, González G, Hernández A, Galindo JM, García MC, et al. Posttranscriptional regulation of the $\beta$ 2-subunit of cardiac L-type $\mathrm{Ca}^{2+}$ channels by microRNAs during long-term exposure to isoproterenol in rats. J Cardiovasc Pharmacol. 2011;58(5):470-8.

42. Jeong G, Lim YH, Kim NJ, Wee G, Kim YK. Knockout of miR-221 and miR222 reveals common and specific targets for paralogous miRNAs. RNA Biol. 2017;14(2):197-205. https://doi.org/10.1080/15476286.2016.12699 94.

43. Ramalingam P, Palanichamy JK, Singh A, Das P, Bhagat M, Kassab MA, et al. Biogenesis of intronic miRNAs located in clusters by independent transcription and alternative splicing. RNA. 2014;20(1):76-87.

44. Ryazansky SS, Gvozdev VA, Berezikov E. Evidence for post-transcriptional regulation of clustered microRNAs in Drosophila. BMC Genomics. 2011. https://doi.org/10.1186/1471-2164-12-371.

45. Grune T, Ott C, Häseli S, Höhn A, Jung T. The, "MYOCYTER"—convert cellular and cardiac contractions into numbers with ImageJ. Sci Rep. 2019;9(1):1-13.

\section{Publisher's Note}

Springer Nature remains neutral with regard to jurisdictional claims in published maps and institutional affiliations.
Ready to submit your research? Choose BMC and benefit from:

- fast, convenient online submission

- thorough peer review by experienced researchers in your field

- rapid publication on acceptance

- support for research data, including large and complex data types

- gold Open Access which fosters wider collaboration and increased citations

- maximum visibility for your research: over $100 \mathrm{M}$ website views per year

At BMC, research is always in progress.

Learn more biomedcentral.com/submissions 